\title{
Implementing STI/HIV prevention and care interventions for men who have sex with men in Senegal
}

Amadou Moreau

Placide Tapsoba

Population Council

Abdoulaye Ly

Cheikh Ibrahima Niang

Abdou Khoudia Diop

Follow this and additional works at: https://knowledgecommons.popcouncil.org/departments_sbsr-hiv

Part of the Demography, Population, and Ecology Commons, Family, Life Course, and Society

Commons, International Public Health Commons, and the Medicine and Health Commons

How does access to this work benefit you? Let us know!

\section{Recommended Citation}

Moreau, Amadou, Placide Tapsoba, Abdoulaye Ly, Cheikh Ibrahima Niang, and Abdou Khoudia Diop. 2007. "Implementing STI/HIV prevention and care interventions for men who have sex with men in Senegal," Horizons Research Summary. Washington, DC: Population Council. 


\section{IMPLEMENTING STI/HIV PREVENTION AND Care InTERVEnTIONS For MEN WHO Have Sex with Men in Dakar, Senegal}

$\mathrm{E}$ xploratory research conducted by the Horizons Program in 2002 revealed that men who have sex with men in Dakar, Senegal, are particularly vulnerable to sexually transmitted infections (STIs) and HIV because of high rates of unprotected anal sex, a history of STI symptoms, and poor knowledge of STIs. Further, the stigma and discrimination suffered by many men who have sex with men result in the concealment of sexual behaviors from health care providers, making it difficult for this population to receive appropriate services. Finally, there is a lack of HIV prevention campaigns geared to this group, as key messages disseminated in the country have largely focused on heterosexual transmission (Niang et al. 2002).

In response to these findings, key stakeholders in Dakar worked together to develop and implement an intervention to meet the STI/HIV prevention needs of men who have sex with men, and to address prevailing stigma that effectively serves as a barrier to care. The intervention had three components:

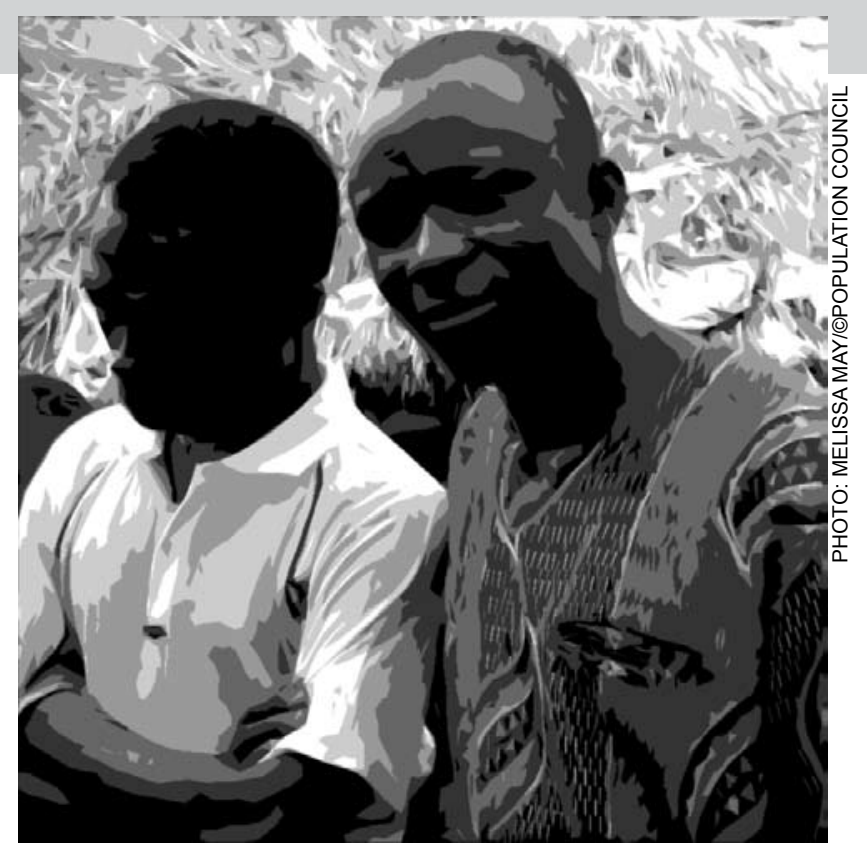

Many men who have sex with men in Dakar, Senegal are at risk of STIs and HIV.

- Peer education to improve HIV prevention knowledge and increase prevention and health-seeking behaviors.

- Diagnosis and treatment of STIs, and HIV counseling and testing, through accessible and "friendly" health services.

- Education and sensitization of the media about issues facing men who have sex with men.

The AIDS/STI Division within the Ministry of Health coordinated the intervention with several partner institutions, including Africa Consultants International, the National AIDS Alliance (ANCS),

To read more about this study, go to www.popcouncil.org/horizons/projects/Senegal_MSMHealthNeeds.htm
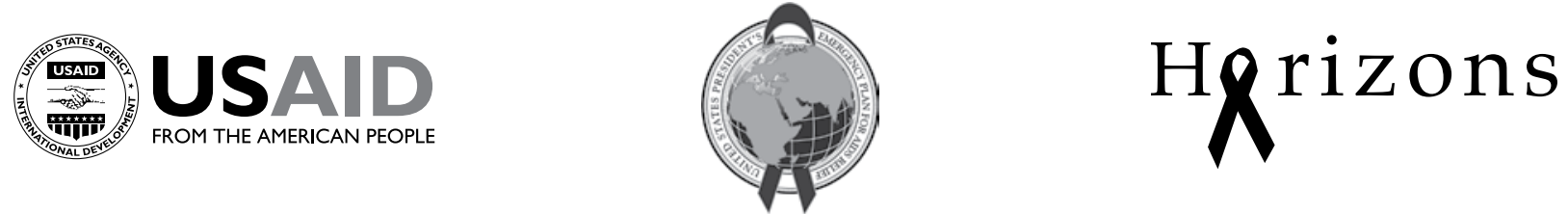
the Institute of Social Hygiene (IHS), ENDA Santé, and Family Health International. The Horizons Program, in collaboration with the Institute of Environmental Sciences/Cheikh Anta Diop University in Dakar assessed the feasibility and acceptability of the intervention, and its outcomes on the target group. This paper summarizes the key findings from the research, and the challenges and lessons learned from implementing an intervention to meet the needs of men who have sex with men.

\section{Description of the Intervention Components}

\section{Peer education}

ANCS, an affiliate of the International HIV/AIDS Alliance, was the lead partner in implementing the peer education component. ANCS coordinated the recruitment and training of 40 men to serve as leaders and peer educators to improve knowledge about HIV prevention, and increase preventive and health-seeking behaviors among men who have sex with men. Selection criteria for the peer educators included an ability to mobilize other men, leadership and communication skills, and an understanding of and agreement with the aims of the project. The peer educators received a small stipend for their work.

Working with peers in their network one-on-one and in groups, the peer educators encouraged regular condom use and the avoidance of unprotected penetrative sex, distributed condoms and shared information about where to get them, and provided referrals to specially designated health providers, including those from IHS, who were trained to provide destigmatizing STI/HIV services to men who have sex with men.

In addition, the peer educators informed the men in their networks about the existence of two support groups, And ligeey and ADAMA, which were either started or strengthened with the help of ANCS during the project period. The project team also intended for the peer educators to distribute water-based lubricants, but encountered problems in securing a steady supply throughout the intervention period (see Challenges and Lessons Learned).

\section{STI and HIV services}

This component aimed to improve access to health services by men who have sex with men in order to reduce the spread of STIs, including HIV. The AIDS/STI Division of the Ministry of Health, with support from Family Health International, created and trained a network of health providers who were sensitized to the special needs of men who have sex with men, and who were available to provide confidential, non-judgmental medical and psychosocial care. This included HIV voluntary counseling and testing (VCT), diagnosis and treatment of STIs, and referrals for antiretroviral therapy (ART).

In Dakar, the network included providers from IHS as well as five other physicians from the public sector who offered to see and treat men who have sex with men. Another seven physicians from outside of Dakar also joined the network during the study period. Men who have sex with men learned about these providers from the peer educators and the data collection facilitators (see Research Methods), who sometimes accompanied them when seeking services.

\section{Education and sensitization of the media}

Findings from the exploratory research pointed to the need to educate and sensitize different societal groups to the HIV prevention and care needs of men who have sex with men, and the deleterious effects of stigma, discrimination, and violence on this population. The project team focused on representatives of the media as a conduit for reaching other key stakeholders, such as the police and community leaders. In August 2003, the project held a two-day, residential workshop for media representatives in Saly, outside of Dakar. The workshop brought together 29 participants from 20 media groups, including 15 print journalists and reporters from four radio and two television stations. Also in attendance were a sociologist, a sexologist, two men who have sex with men to share their personal experiences, the Head of the AIDS/STI Division of the Ministry of Health, and the organizers. The workshop included presentations on the results from the exploratory study and findings from a five-year review of news articles from Senegal on men who have sex with men. Participants discussed the 
risk of HIV infection among men who have sex with men compared to the general population, the contribution the media can make in supporting HIV and STI prevention and care programs, the quality and ethics of media information gathering in Senegal, and the need for fair, unbiased, and accurate reporting.

\section{Research Methods}

The study used a pre-test/post-test research design to assess the outcomes of the intervention on men who have sex with men. The research team first conducted mapping activities in the Dakar area to determine where men who have sex with men could be found. They then selected 12 men from various networks identified through the mapping activities to serve as data collection facilitators. Specifically, their role was to recruit two separate cross-sectional samples of men using snowball sampling to participate in a structured interview at baseline (May - October 2003) and again at follow up (January - March 2005). These men also helped the research team find suitable places for the interviews so they would be private and confidential.

The men were chosen based on their capacity to mobilize other men and for their ability to adhere to ethical principals when carrying out their responsibilities, including maintaining confidentiality. The facilitators participated in training sessions on quality control and ethics related to data collection, and received a small stipend for their work in recruiting men to be interviewed. In addition to helping with data collection, the facilitators identified men to be trained as peer educators, and some became peer educators themselves.

The baseline sample consisted of 258 men, and the follow-up sample included 290 men. Men were eligible to be interviewed if they were 18 years or older and had ever had sexual relations with another male. Men were first approached by a study facilitator who explained the purpose of the study. If a man agreed to be interviewed, he was given a small amount of money to cover his transportation costs to and from a private location for the interview, which was conducted by a trained member of the research team. The facilitators also referred men whom they approached about the study to IHS if they were concerned about possible STI symptoms.

The research team also conducted qualitative assessments midway through the evaluation process to determine the perceptions of the intervention activities among different groups. A total of 71 individual interviews were conducted with men who have sex with men; 50 interviewees responded to questions about STI/HIV services, and 18 gave their views about the peer education activities. Three doctors were also interviewed in order to better understand the limitations and constraints that impeded the provision of STI/HIV services to men who have sex with men. In addition, six focus group discussions (FGDs) were held with a total of 56 men who took part in peer education activities and/or used the health services set up by the project. All respondents provided oral informed consent prior to participation in the surveys, interviews, and FGDs.

The research team collected process data on the men who accessed services at IHS during the study period (May 2003 to April 2006) and the results of their examinations. A total of 1,206 physical examinations of men who have sex with men were conducted at IHS. These were men who had been referred or accompanied by the data collection facilitators and peer educators.

The study was approved by the Senegal National AIDS Council and the Population Council's Institutional Review Board.

\section{Characteristics of the Survey Samples}

At baseline, the mean age of respondents was 26 years (range: 17-57). The vast majority had never been married (92 percent), yet 14 percent had at least one child. Almost all identified as Muslim. Nearly half of the sample had not gone beyond the primary level of education. Nearly one in five was a laborer or unskilled worker, 20 percent were unemployed, 16 percent were traders, and 11 percent were students. Overall, the sociodemographic characteristics of the men interviewed at baseline and follow up were similar.

\section{Key Findings}

\section{STI/HIV knowledge increased between the beginning and end of the study, but important gaps remained.}

Awareness of the existence of STIs and HIV/AIDS was high at baseline (91 percent), and increased further by the end of the study (99 percent; $\mathrm{p}<.001$ ). Among 
respondents, the number who knew at least three STI symptoms more than doubled from 26 percent to 61 percent $(p<0.001)$. There was also significant improvement in knowing that one can avoid HIV infection by using condoms (87 percent to 93 percent; $\mathrm{p}<0.05$ ). However, knowledge about other ways of avoiding HIV remained low (e.g., limiting oneself to a single partner; 29 percent vs. 23 percent, NS) or decreased further (e.g., having a sexual partner who is not infected; 17 percent vs. 10 percent; $\mathrm{p}<0.05$ )

\section{HIV testing among men who have sex with men increased substantially.}

As shown in Table 1, awareness of a test to detect HIV significantly increased among respondents (52 percent to 83 percent; $\mathrm{p}<0.001)$. This increased knowledge coincided with an increase in the proportion who reported having received an HIV test (16 percent to 64 percent; $\mathrm{p}<0.001)$. Importantly, 80 percent of the men who were tested at follow up returned to get their test results.

Table 1 HIV testing: Awareness and experience

\begin{tabular}{|c|c|c|}
\hline & $\begin{array}{c}\text { Baseline } \\
n=258 \\
n(\%)\end{array}$ & $\begin{array}{c}\text { Follow up } \\
n=290 \\
n(\%)\end{array}$ \\
\hline Heard about HIV testing & $133(52)$ & $242\left(83^{* *}\right)$ \\
\hline Had an HIV test & $21(16)$ & $186\left(64^{* *}\right)$ \\
\hline $\begin{array}{l}\text { Returned to get test } \\
\text { results }\end{array}$ & - & $149(80)$ \\
\hline $\begin{array}{l}\text { Reasons why did not } \\
\text { get tested for HIV }\end{array}$ & $n=112^{\S}$ & $\mathrm{n}=104^{\S}$ \\
\hline Did not get the chance & - & $44(42)$ \\
\hline $\begin{array}{l}\text { Fears knowing his HIV } \\
\text { status }\end{array}$ & $39(35)$ & $14\left(13^{* *}\right)$ \\
\hline $\begin{array}{l}\text { Does not see the need } \\
\text { for testing }\end{array}$ & $24(21)$ & $9\left(9^{*}\right)$ \\
\hline Feels healthy & $16(14)$ & $14(13)$ \\
\hline $\begin{array}{l}\text { Does not know a } \\
\text { testing center }\end{array}$ & $18(16)$ & $35\left(34^{*}\right)$ \\
\hline Other & $12(11)$ & $5(5)$ \\
\hline
\end{tabular}

${ }^{*} p<0.05 ;{ }^{* *} p<0.001$

$\S$ In the baseline survey the number of men who were asked why they did not get tested (112) consisted of the men who had heard of HIV testing (133) minus those who had an HIV test (21). At follow up, those asked to provide reasons for not getting tested (104) was calculated by subtracting the number who tested (186) from the total number of survey respondents (290).
Reasons cited by those who had not been tested included not getting the chance to test, fear of knowing their HIV status, and feeling healthy. Surprisingly, the proportion of respondents who reported not knowing where to find a testing center more than doubled from 16 percent to 34 percent.

\section{The results were mixed for condom use post- intervention.}

At baseline, 73 percent of the men interviewed reported using a condom during their last anal intercourse with another man. This proportion increased to 82 percent at follow up ( $\mathrm{p}=0.01)$. However, when asked about consistent condom use during anal sex for the previous 12 months, there was little change from baseline to follow up (52 percent to 58 percent, NS).

As shown in Table 2, respondents cited many reasons for not using condoms at last anal sex at baseline and follow up, including difficulty finding them, trusting their sexual partners, and the refusal of some partners to use them. But the most common reason at follow up (38 percent) was that sex was unexpected, suggesting that such liaisons were not conducive to having protected anal intercourse. Although the proportion of men reporting difficulties in obtaining a condom decreased from 14 percent at baseline to 7 percent at follow up, increased access to condoms might make it more likely that men would have condoms available for such unexpected liaisons.

The vast majority of men in both surveys reported ever having had sexual intercourse with a woman $(88$ percent and 91 percent, respectively). When asked about condom use during the previous 12 months, less than half of these respondents at both baseline and follow up reported using a condom with a woman during anal intercourse ( 41 percent and 42 percent) and during vaginal intercourse ( 45 percent and 49 percent).

\section{Consistent use of water-based lubricants was low.}

There was a significant increase in the number of respondents who reported using water-based lubricants, from 51 percent at baseline to 70 percent at follow up $(\mathrm{p}<0.0001)$. When users of water-based lubricants were asked about consistent use, only 22 percent at baseline 
Table 2 Reasons for non-use of condoms during last anal sex with a man

\begin{tabular}{lcc}
\hline & $\begin{array}{c}\text { Baseline } \\
(\mathbf{n}=\mathbf{6 6}) \\
\%\end{array}$ & $\begin{array}{c}\text { Follow up } \\
(\mathbf{n}=\mathbf{5 8}) \\
\%\end{array}$ \\
\hline Condom is unobtainable & 14 & 7 \\
Partner does not want to use it & 23 & 23 \\
Does not like the condom & 38 & $7^{*}$ \\
Sexual relations were unexpected & 12 & $38^{*}$ \\
Have confidence in their partners & 9 & 17 \\
Others & 6 & 9 \\
\hline${ }^{*} \mathrm{p}<0.001$ & \multicolumn{3}{c}{}
\end{tabular}

* $p<0.001$

and 35 percent at follow up said that they used them every time they engaged in anal sex with another man.

The men surveyed often resorted to products other than commercial, water-based lubricants (see Table 3). Vaseline, an oil-based lubricant which is not compatible with condoms was most often used, and the use of this product during anal sex increased considerably between the two surveys, from 11 percent to 34 percent. Shea butter and saliva were also used in many cases; 22 percent of respondents at follow up said they used each one.

Low use of water-based lubricants may be partly explained by the challenge of accessing the product and shortages in the market. At follow up, more than four in ten men ( 43 percent) reported difficulties finding them.

Respondents using water-based lubricants said that they preferred buying them from drug stores. However, the high cost of water-based lubricants sold in pharmacies (approximately US\$10.00/tube) and the low purchasing power of many of the men interviewed likely made their consistent use problematic.

\section{HIV prevalence was high among men who sought HIV testing as part of STI services.}

During the study period, a total of 1,206 men who have sex with men sought services at IHS. Among these men, a total of 145 cases of STI symptoms were diagnosed and treated. This included 89 cases of genital discharge, 49 cases of genital/anal sores, and seven cases of genital ulcers. A total of 263 men requested HIV testing, of which 88 tested positive for HIV (33 percent). Among these men, 81 were referred to a government outpatient center that offers treatment, care, and support to HIVpositive individuals, and seven others did not return for their results.

\section{Men appreciated the availability of STI services that were high quality and non-stigmatizing.}

The provision of services would not have been possible without the determination of qualified and committed medical personnel who provided men with high quality services that were not stigmatizing or discriminatory. Comments attesting to the skill with which the clinicians interacted with men who have sex with men were frequent during the FGDs:

The polyclinic [IHS] is a discreet location and the medical officers are very kind and available to attend to us... if we had been mistreated, it is obvious that we would not have returned. We are very much welcomed and made to feel comfortable. We receive counseling which is very vital to us because it is directly related to our activities. We also obtain condoms and lubricants to better protect ourselves from diseases. Honestly speaking, all the medical officers there are exemplary.

25-year-old male

They are doing a wonderful job because they are available when we need them and they are not judgmental.

23-year-old male

\section{A collaborative approach to the media was well received by journalists.}

A component of the intervention involved working in collaboration with the media to provide quality information, to raise the general public awareness, and to reduce discrimination toward men who have sex with men. As mentioned above, a workshop for the exchange of information and discussion was organized, which brought together journalists from various media in Senegal, partners in the implementation of the intervention, and stakeholders involved in HIV work in Senegal. Men who have sex with men participated in the workshop in order to bring a human face to the issues and allow journalists to better understand the hidden realities of the men's lives. 
Table 3 Types of lubricants used during anal sex (excluding commercial, water-based lubricants)

\begin{tabular}{lcc}
\hline & $\begin{array}{c}\text { Baseline } \\
(\mathbf{n}=\mathbf{1 6 5}) \\
\%\end{array}$ & $\begin{array}{c}\text { Follow up } \\
(\mathbf{n}=\mathbf{2 0 2})\end{array}$ \\
\hline Vaseline & 1 & $34^{* *}$ \\
Shea butter & 8 & $21^{* *}$ \\
Saliva & - & 22 \\
Beauty lotion & - & 19 \\
Gel/Shaving cream & 5 & 9 \\
Butter/Cooking oil & 2 & 3 \\
Other lubricating products & 11 & $4^{*}$ \\
\hline${ }^{*} p<0.05 ;{ }^{* *} p<0.001$ & &
\end{tabular}

The participation of men who have sex with men in the workshop was also designed to reduce their suspicion of journalists, to improve their perception about the work journalists do, and to establish an atmosphere of collaboration between them. Initially, these participants did not reveal their identities. However, the discussions gave them the confidence to speak up and they voluntarily shared their experiences about stigma, discrimination, and violence, and their powerful stories had an impact on everyone present.

During the 18-month period after the workshop, the project team found that there had not been any offensive or stigmatizing articles written about men who have sex with men, including in the tabloid press.

\section{Challenges and Lessons Learned}

\section{Although the retention rate was high among peer educators, limited supervision and monitoring of their activities impeded progress.}

At the beginning of the study, 40 men were recruited and trained as peer educators. By the end of the study, only two had dropped out. Despite a high level of retention, there were a number of challenges that affected the peer educators' performance. Some peer educators found it difficult to gain the acceptance and trust of their peers. Others feared possible disclosure of their sexual identity to family members as a result of their involvement in the project, and therefore were not as active as expected.
Many found managing the men in their group sessions and staying on course challenging. Further, the peer educators were not well equipped to monitor the activities they conducted and report accurately how many men attended and what was discussed, which hindered the overall assessment of this intervention component. Better supervision of peer educators could have contributed to taking necessary steps in a timely manner, such as providing additional training or re-thinking job responsibilities, to limit the inadequacies that occurred.

Another challenge concerned the capabilities of the peer educators. The project team aimed to select peer educators based on their capacity to mobilize other men who have sex with men, and their leadership and communication abilities. In reality, however, the candidates were often selected by the facilitators based on cronyism. Better monitoring and supervision by implementation partners would have been beneficial for identifying unproductive peer educators and recruiting men with better skills and more interest in the aims of the project.

\section{The intervention did not reach "invisible" men.}

Informants noted that intervention activities failed to reach "invisible" men. This term refers to older men, often of a higher socioeconomic status, who are very concerned about keeping their sexual activities confidential to protect jobs and family. One respondent explained this self exclusion:

There are older Ibbis [one group of men who have sex with men] that my friends and I visit and sometimes they ask us questions about the project activities... and it happens that they would like to take part in these activities but are afraid to do so. They are not as bold as that. It must also be understood that we do not belong to the same generation and the realities are not the same.

22-year-old peer educator

Another informant noted the importance of targeting older men because they may have more money and hence more power in a sexual relationship:

...the old ones... attract the young ones with money. And where money is available, the young Ibbi can forget everything about prevention. That is the reason why it is necessary to involve the older Ibbis as well in the awareness-raising program.

23-year-old male 
Future efforts should focus on recruiting older men as peer educators as well as using other communication channels, such as a telephone hotline or the internet, to inform and mobilize this population.

\section{Men had very limited access to free or moder- ately priced water-based lubricants.}

The baseline data highlighted the need to increase men's access to water-based lubricants. The project contacted many potential donors to receive supplies but only received a small amount from a private Belgian donor. These were distributed during the first peer educator training sessions conducted by ANCS. No further donations were obtained; thus the only option was purchasing the product from a pharmacy where it was very expensive (about US $\$ 10.00$ for a tube).

\section{Changing donor priorities impeded the imple- mentation of planned activities.}

Because of the political sensitivities associated with men who have sex with men, donors were not always consistent in their support of the project. Consequently, the implementing partners who counted on receiving funds for project activities were subject to donorspecific constraints, including funding interruptions. For example, the project initially planned to conduct a series of sensitization and training activities with the police to decrease stigma and violence perpetrated by them against men who have sex with men. However, funding limitations resulted in the cancellation of these activities. Funding interruptions experienced by the partners also created coordination problems, which interfered with a streamlined effort to conduct activities. In the future, as interventions for men who have sex with men are implemented in other countries, donor concerns (and concerns of host governments and other key players) should be addressed early on, prior to study implementation, to ensure the uninterrupted implementation of project activities.

\section{The aims of the project were sometimes misun- derstood by participants to include economic benefits.}

Some respondents thought that by participating in the program they would receive financial gain, such as jobs or training. Others felt that future efforts should include training and professional development for the study population, given their low levels of education and frequent reliance on trading sex for economic gain. As one respondent stated:

...you should help us to quickly find jobs because we are living in a dire situation and are rejected by society. No one supports us. If that is not possible, you should at least provide us with funding to undertake income-generating activities.

33-year-old male

Programs need to clearly communicate what is and what is not offered as a result of participation. At the same time, programs could identify economic and educational resources and opportunities in the community and make sure peer educators are aware of them in order to communicate their availability to others.

\section{Conclusions}

This was one of the first intervention studies to address the HIV and sexual health needs of men who have sex with men in Africa. The study highlights both gains and limitations of the intervention strategies implemented. On the one hand, the project was able to recruit and retain men to serve as peer educators to disseminate information and condoms to their peers. In addition, the project was able to recruit health providers to offer high quality, non-stigmatizing STI services to men who have sex with men, and to engage the media in a discussion about how they can play a more constructive and less stigmatizing role in fostering HIV prevention among men who have sex with men and their partners.

On the other hand, there were clear problems with recruiting appropriate leaders to carry out peer education activities, providing adequate training and supervision, and ensuring adequate supplies of lubricants compatible with condom use. In addition, the project had limited success in reaching older men, including those of higher socioeconomic status. Moreover, there was uneven support for the program by intervention partners as a result of wavering donor commitment to address the needs of men who have sex with men.

The quantitative data suggest some improvements over time among the study population, such as in HIV/STI knowledge, condom use at last sex, and uptake of HIV testing, which may reflect accomplishments of the inter- 
vention as well as positive secular changes. However, the survey data highlight other areas that remained problematic, (e.g., such as limited condom use with women), or that worsened from baseline to endline (e.g., the use of Vaseline as a lubricant).

In order to move ahead in Senegal and in other regions of Africa, it is clear that political and donor commitment are key to effectively addressing the HIV-related needs of men who have sex with men. While the extent to which sexual activity among men contributes to the HIV epidemic in Africa is unknown, it is clear that certain behaviors increase this population's risk and that of their female sexual partners, and that there are few resources committed to men who have sex with men in many countries in the region. Political and donor commitment therefore are critical, because each can facilitate the smooth collaboration between implementing partner organizations, ensure the continued availability of products and technologies such as condoms and appropriate lubricants, support the creation and sustainability of non-stigmatizing health services, and help curb stigma, discrimination, and violence perpetuated by different actors in the community through sensitization and educational activities.

Another important area to address is that of capacity building. For many implementing organizations, working with men who have sex with men may be new, or organizations made up of men who have sex with men may be just getting off the ground. For both types of groups, capacity building around community mobilization, peer education, monitoring and evaluation, supervision and support, and participatory approaches needs to be considered.

\section{Research Utilization}

In response to this study, the Senegal National AIDS Council is providing financial support to NGOs to work with men who have sex with men, using both World Bank and the Global Fund to Fight AIDS, Tuberculosis, and Malaria resources. Findings from this project and the earlier diagnostic study have informed the work of other groups working to address the HIV-related needs of men who have sex with men in countries such as Ghana, Mali, Burkina Faso, the Gambia, and Côte d'Ivoire, with funding provided by the Bristol MyersSquibb Foundation and the World Bank's Multi-country AIDS Program (MAP). $\mathbf{X}$

December 2007

\section{References}

Niang, Cheikh I. et al. 2002. "Meeting the sexual health needs of men who have sex with men in Senegal," Horizons Final Report. Washington, DC: Population Council.

\begin{abstract}
This work was made possible through the efforts and contributions of several institutions and the commitment of a number of people. Dr. Abdoulaye Ly, in his capacity as Head of AIDS/STI Division Senegal (Ministry of Health) provided invaluable insights, guidance, and support throughout the project. We also thank all the partner institutions that contributed to the implementation of this study. We express our gratitude to the individual men who voluntarily participated in the surveys; without their contribution, this study will not have been possible.
\end{abstract}

We thank all members of the research team: Ndèye Fatou Ngom Guèye, Moustapha Diagne, Alioune Fall, Abdoulaye Sidibé Wade, Ababacar Thiam, Thomas Lax, Tidiane Kassé and Youssoupha Niang. Our special appreciation goes to the facilitators who spared no effort to assist in the gathering of information, often in difficult circumstances.

Finally, we would like to thank all those who contributed to the implementation of this project.

Study investigators include: Amadou Moreau and Placide Tapsoba, Horizons Program/Population Council; Abdoulaye Ly and Abdou Khoudia Diop, AIDS/STI Division, Ministry of Health Senegal; Cheikh Ibrahima Niang, Institute of Environmental Sciences, Cheikh Anta Diop University.

Suggested citation: Moreau, Amadou, Placide Tapsoba, Abdoulaye Ly, Cheikh Ibrahima Niang, and Abdou Khoudia Diop. 2007. "Implementing STI/HIV prevention and care interventions for men who have sex with men in Senegal," Horizons Research Summary. Washington, DC: Population Council.

\section{Hprizons} Population Council/

Horizons Communications Unit 4301 Connecticut Avenue, NW Suite 280 Washington, DC 20008

\section{Population Council}

Tel: 202-237-9400

Fax: 202-237-8410

horizons@popcouncil.org

www.popcouncil.org/horizons
This research summary is made possible by the generous support of the American people through the United States Agency for International Development (USAID) and the President's Emergency Plan for AIDS Relief under the terms of HRN-A-00-97-00012-00. The contents are the responsibility of the Horizons Program and do not necessarily reflect the views of USAID or the United States Government.

๑2007 The Population Council Inc. 